\title{
An anatomical study of developmental changes in maturing root tissues of pomegranate (Punica granatum L.) and formation of a unique type of periderm
}

\author{
Astha Tuladhar and Naosuke Nii \\ Faculty of Agriculture, Meijo University, Nagoya 468-8502, Japan \\ Corresponding author: N. Nii, E-mail: nii@meijo-u.ac.jp, Phone: +81-52-838-2435
}

Received on March 24, 2014; Accepted on July 10, 2014

\begin{abstract}
Roots of pomegranate (Punica granatum L.), belonging to Punicaceae, were investigated anatomically to record changes in tissue development from growth to maturity. When roots start secondary growth, a protective tissue called polyderm composed of alternating suberized and non-suberized cell layers, develop beyond the endodermis in certain families of plants including Myrtaceae. Punicaceae family is not known to develop a polyderm. However, new layers formed beyond the endodermis during secondary growth and biopolymer deposition was observed in their cell walls. The present study aims to gather more knowledge on this tissue discovered in pomegranate roots and cross check whether it is a polyderm or a unique type of periderm.

Root specimens were sectioned freehand or with an ultramicrotome after embedding in Technovit 7100 resin. After staining with berberine hemisulfate-aniline blue-safranin $\mathrm{O}$, the root sections were observed under fluorescent or optical microscopes.

Unlike the polyderm in Myrtaceae roots, in pomegranate roots, ligno-suberic material accumulated in every cell layer beyond the endodermis. The alternating suberized and non-suberized layers that define the polyderm were absent. Lignin accumulation in the cell wall was pronounced in every cell layer of this outermost tissue and suberin-like autofluorescence was also observed in the same layer. We considered this to be a unique feature typical in pomegranate periderm.

It is possible that accumulating both lignin and suberin in the same cell layer instead of alternative layers is more efficient because metabolic energy is not spent in forming a separate cell layer. Further experiments are
\end{abstract}

underway to acknowledge changes in such biopolymer accumulation in the outermost tissue in abiotic stress conditions.

Keywords: lignin, suberin, rhizodermis, exodermis, thick-walled cells, polyderm, Punicaceae

\section{Introduction}

Pomegranate (Punica granatum L.) belongs to Punicaceae family of plants. It is an oldest known edible fruit tree species originating from central Asia which is now produced worldwide for its highly recognized medicinal, nutritional and ornamental properties (Teixeira da Silva et al. 2013). Its adaptive characteristics reflect in its geographically wide distribution. Roots are directly affected by different soil environments. Maintaining a healthy root system is crucial for a steady yearly production, especially in the case of deciduous fruit trees such as pomegranates that relies on starch deposited in roots over winter. Unfortunately, there is very limited data on pomegranate roots. A study on pomegranate root distribution was reported recently by Hiwale et al. (2011) but an anatomical study like the present study is still rare. One reason could be because pomegranates are known to have toxic bark and roots (Tripathi and Singh 2000).

In this study, pomegranate roots were investigated anatomically to gain basic knowledge of root tissue development from growth to maturity. Recording changes that occur during root growth may further clarify tissue function and point out interesting characteristics unique to pomegranate roots. In the past, we have reported similar works in grapevine roots (Song et al. 2011b) with special focus on the Casparian strip. In the present study, our focus is mainly on biopolymer accumulation during periderm formation. 
Early observations on polyderm were reported by Luhan (1955) in Unserer Alpenpflanzen and by Nelson and Wilhelm (1957) and Mann (1930) in strawberry roots. Esau (1970) described polyderm as a protective tissue composed of alternating suberized and non-suberized cell layers. According to Esau (1970) polyderm is found in only a few plant families such as Myrtaceae, Hypericaceae, Onagraceae and Rosaceae families but Punicaceae was not mentioned.

Recently, we studied the roots of feijoa (Feijoa sellowiana) belonging to Myrtaceae and reconfirmed the features of the polyderm development (Nii et al. 2012). Based on our observations, polyderm in feijoa roots formed due to the division of a single-layered pericycle into three layers at a time. Lignin accumulated in the outermost layer, immediately beyond the endodermis, and we called that layer thick-walled cell layer (twc). Suberin accumulated in the middle layer forming the Casparian strip, so we called that layer endodermis-like cell layer (el). The innermost layer retained the pericyclic characters, and it divided further to form a new set of three layers. During this observation, our attention was drawn to the accumulation pattern of lingo-suberic materials. At the polyderm, biopolymers mainly lignin and suberin accumulated on opposite sides of the cell wall in two separate cell layers. Lignin-like deposit was "closed" centripetally resembling the letter " $w$ " at the thick-walled cells whereas suberin-like deposit was "open" centripetally resembling the letter " $\mathrm{m}$ " at the endodermis-like cells and this accumulating pattern was commonly detected in roots of five Myrtaceae species (unpublished data).

For woody roots, accumulation of biopolymers such as lignin and suberin is of particular importance because it is known to protect plants from fungal diseases and insect attacks (Moerschbacher et al. 1900, Nelson and Wilhelm 1957, Williamson 1984). The accumulation of biopolymers such as lignin and suberin is a species-specific genetic feature and seems to be useful as a barometer to distinguish species. For example, phi-thickening is a kind of lignin accumulation found in Rosaceae species such as apples (Mackenzie 1979) and loquats (Nii et al. 2004, Pan et al. 2006). In addition, our data shows that unfavorable growth conditions like flooding or drought affects the accumulation of these biopolymers. Our studies revealed that under drought conditions, phi-thickenings developed markedly in cortex cells of loquat trees (Nii et al. 2004, Pan et al. 2006). Similarly, in cortex of red bayberry roots, crescent-shaped lignin accumulation increased under drought stress (Song et al. 2011a). Thus we felt the need to trace the biopolymer accumulation in root tissues of pomegranate roots from growth to maturity.
In this preliminary study, pomegranate roots grown in normal condition were continuously sectioned from the root tip to basal area to examine 1) the accumulation of lingo-suberic material in root tissues such as rhizodermis/epidermis (ep), exodermis (ex), cortex (co), and endodermis (en) and 2) the periderm formation process during secondary growth. The results obtained from this observation are intended to be used for further stress-response related experiments. Compared to the polyderm found in Myrtaceae, in pomegranate roots, the alternating layers of suberized and non-suberized layers described as polyderm did not occur. Instead a cell layers with heavy lignin-like accumulation was observed in the outermost cell layers. In the recent years, root biology is steadily gaining attention. In such a context, the present study about biopolymer accumulation in protective root tissues of woody roots during its maturing phases is highly appropriate to broaden our knowledge about its function which still needs much clarification.

\section{Materials and Methods}

Approximately ten-year-old pomegranate trees (cv. 'Wonderful') which were propagated from cuttings and grown under normal conditions in a greenhouse at Meijo University were used for the present investigation. The pomegranate cuttings were grown in plastic pots (13 cm wide and $11 \mathrm{~cm}$ deep) filled with sandy soil and watered when the upper surface of the soil became dry. The growth of pomegranate trees was dwarfed like bonsai by using small-sized plastic pots. Roots were collected from twenty different trees for observation. To collect roots, plants were removed from the pots and only roots with new white root tips were collected from the root tip to basal area.

Hand-sections of roots were prepared by using a new stainless steel razor blade. Serial transverse sections, commencing at approximately $5 \mathrm{~mm}$ from the root tip toward the basal portion of the root, were cut at $10 \mathrm{~mm}$ intervals to examine changes in structural development as roots matured.

Root specimens were examined under fluorescent microscopy (excitation wavelength $365 \mathrm{~nm}$ ) with or without staining. Several different staining solutions, including berberine hemisulfate-aniline blue-safranin O were used (Brundrett et al. 1988). Lux et al. (2005) reported a novel method for simultaneously clearing and staining tissues in which the fluorochrome $0.1 \%$ berberine hemisulfate was dissolved in a clearing mixture consisting of pure lactic acid saturated with chloral hydrate. We used this method and incubated the root sections in $0.1 \%$ berberine hemisulfate solution at $40^{\circ} \mathrm{C}$ for 30 minutes. The sections were then counterstained with $0.5 \%$ aniline blue (dissolved 
in $\mathrm{H}_{2} \mathrm{O}$ ) at room temperature for 30 minutes followed by saffranin $\mathrm{O}$ for 1 minute. All specimens were then placed on a drop of $\mathrm{H}_{2} \mathrm{O}$ on a slide glass and observed under ultraviolet light using fluorescent microscopy.

Parts of same root samples used for hand sectioning were fixed in $3 \%$ glutaraldehyde (TAAB Laboratories, England, UK), in $0.1 \mathrm{M}$ cacodylate buffer, (Sigma Aldrich, Japan, pH 7.2) and stored at $4^{\circ} \mathrm{C}$ to examine the anatomical features of cell development. The samples were then dehydrated through graded ethanol series and embedded in Technovit 7100 resin (Heraeus Kulzer GmbH, Wehrheim, Germany). Semi-ultra thin sections (1.5 $\mu \mathrm{m})$ were cut using a glass knife then stained with methylene blue for histological examination under a BX 60 optical microscope (Olympus, Tokyo, Japan).

Root age was determined by surface color (i.e., white roots are young and brown roots are old) and by the distance from the root tip. Although more than twenty roots were sectioned and observed, a representative root was selected for report since the basic anatomical features were similar among root samples.

\section{Results}

Accumulation of lingo-suberic material in pomegranate root tissues

A scanned view of representative main root is presented as Fig. 1. The markings on it are the areas where root specimens were collected for observation on the main root. It is clear that the new root is white up to Fig. 1D and as it matures, it gradually turns brown beyond this point. The developmental changes in root tissues were examined one by one. The rhizodermis appeared to be reddish-orange at a distance of $10 \mathrm{~mm}$ from the root tip implying lignin-like accumulation in its cell wall (Fig. 2A). At a distance of $20 \mathrm{~mm}$ from the root tip, the exodermis appeared to be milky white color implying suberin-like phenolic substance deposit in its cell wall (Fig. 2B). At a greater distance from the root tip, a clearer Casparian strip was visible in the exodermis (Figs. 2B-2F). It is clear from this observation that in young, new roots, the exodermal Casparian strip forms in one or more layers of the exodermis as roots mature (Figs. $2 \mathrm{E}$ and $2 \mathrm{~F}$ ). In Fig. 3, the developmental changes in the endodermis are presented. These developmental changes in the endodermis could be divided into successive stages I, II, III as Lux and Luxova (2001) and Mackenzie (1979) have done to study endodermis. Endodermal cells of vascular plants may develop in three developmental states resulting in primary, secondary or tertiary endodermis, respectively (von Guttenberg 1968). At a distance of $20 \mathrm{~mm}$ from the root tip, a small line-like Casparian strip appeared at

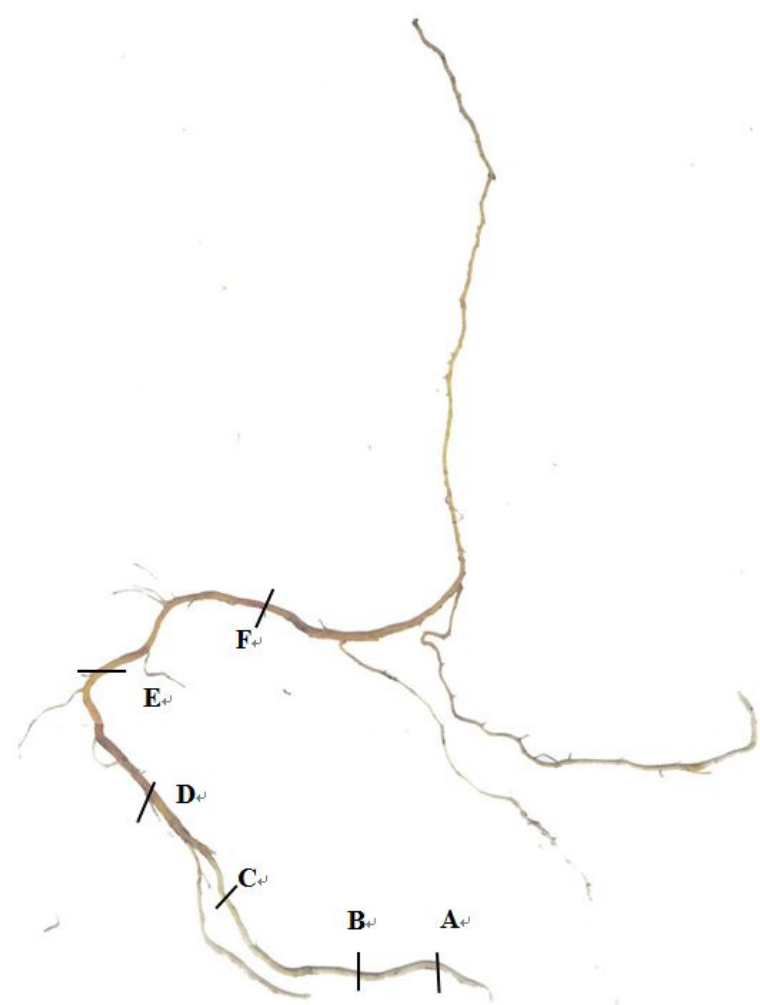

Fig. 1. A scanned view of representative pomegranate main root illustrating growth from new white roots to old roots. The markings, A-F, indicate the area where cross-sections in Figs. 2 A-F were cut at a distance of $10,20,60,80,110,140 \mathrm{~mm}$, respectively. Cross-sections of Figs. 3 A-F were also prepared from the same root but panel names and distance from the root tip are named differently.

the endodermis initially (Fig. 3A). This stage was termed stage I since differentiation of the Casparian strip occurred. At a greater distance from the root tip, suberin accumulated in the entire cell wall at the endodermis (Figs. 3B and 3C). This stage was termed stage II since all wall areas got suberized. Eventually, the Casparian strip was observed at both the exodermis and the endodermis (Figs. 2B and 3B). At the exodermis, Casparian strip developed at a distance of $20 \mathrm{~mm}$ from the root tip (Fig. 2B) whereas at the endodermis, it developed at $60-80 \mathrm{~mm}$ from the root tip (Figs. 3B and 3C). It was clear that the Casparian strip developed earlier at the exodermis than the endodermis. From the distance of about $80 \mathrm{~mm}$ (Fig. $3 \mathrm{C}$ ), some cells in the cortex surrounding the endodermis accumulated lignin in the cell wall. Such cortical cells accumulating lignin increased at a greater distance from the root tip (Figs. 2F and 3F). This kind of lignin accumulation was similar to crescent-thickening in cortical areas of red bayberry roots (Song et al. 2011a). 

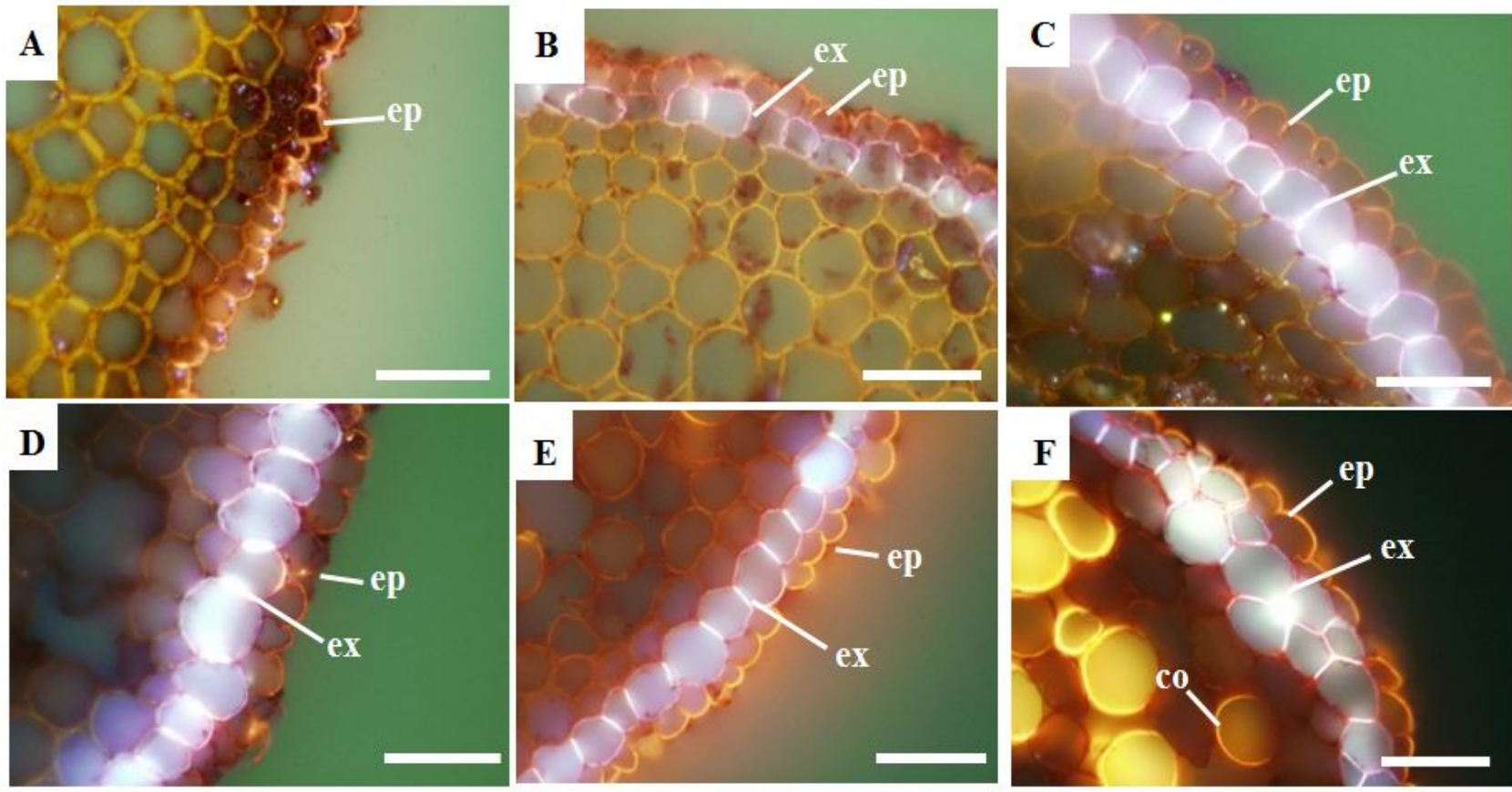

Fig. 2. Lignin-like deposit in the rhizodermis and suberin-like deposit and Casparian strip formation at the exodermis in relation to pomegranate root age. Root samples were stained with berberine hemisulfate-aniline blue-safranin O. Lignin encrusted rhizodermis turned reddish orange under the fluorescent microscope and suberized areas in exodermis appeared milky white. Casparian strip formed in one or more layers at the exodermis. Distance from the root tip, panel A: $10 \mathrm{~mm}, \mathrm{~B}: 20 \mathrm{~mm}, \mathrm{C}: 60$ mm, D: 80 mm, E: 110cm, F: 140 mm. ep: rhizodermis/epidermis; ex: exodermis; co: lignified cortical cell. Scale $=50 \mu \mathrm{m}$.
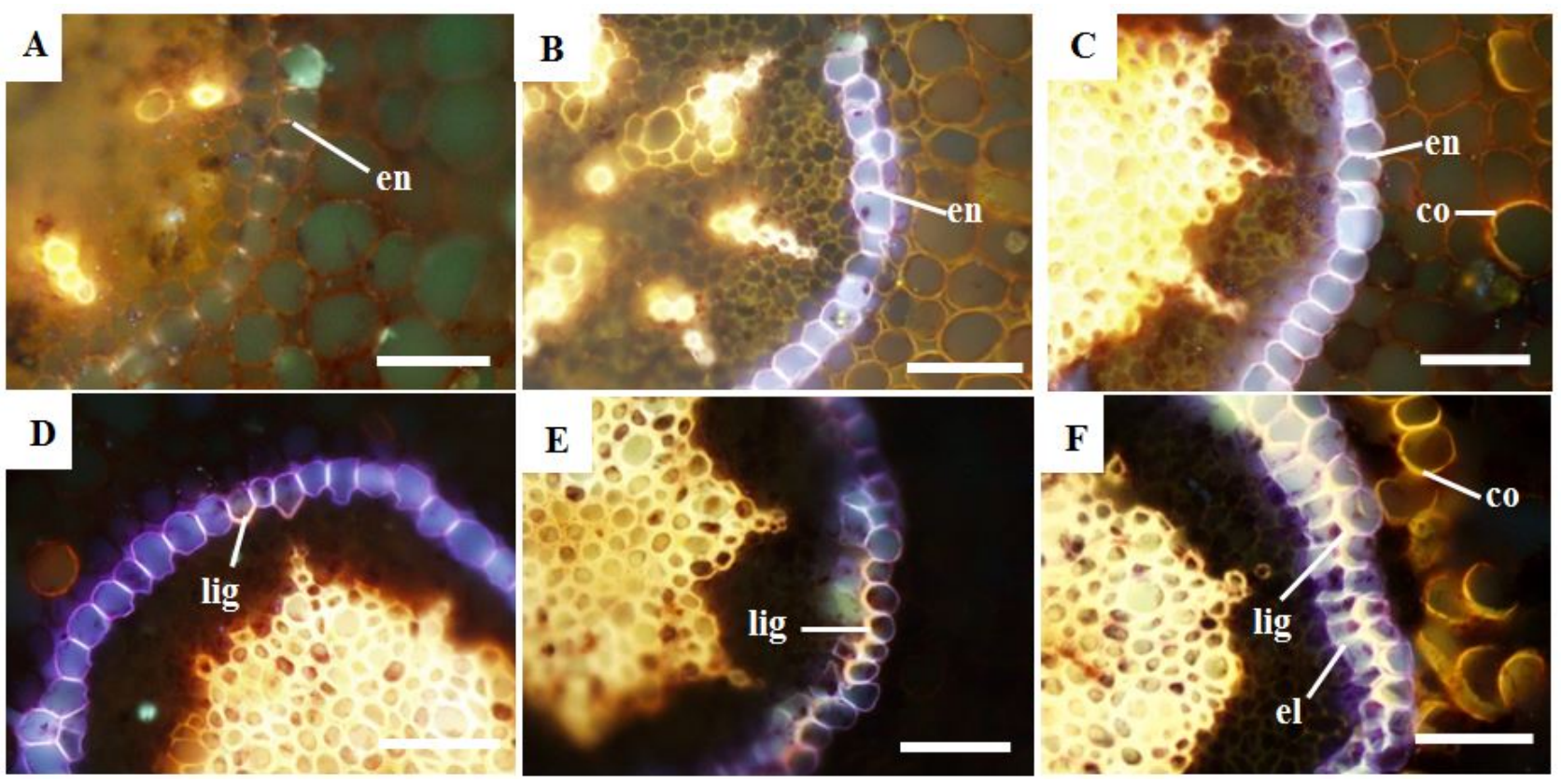

Fig. 3. Suberin accumulation and development of Casparian strips in the endodermis and formation of the first new layer with lignin-like accumulation beyond the endodermis in pomegranate roots. Root samples were stained with berberine hemisulfate-aniline blue-safranin O. Lignin encrusted cortical cells and few endodermal cells appear reddish orange. Distance from the root tip, panel A: $20 \mathrm{~mm}, \mathrm{~B}: 60 \mathrm{~mm}, \mathrm{C}: 80 \mathrm{~mm}, \mathrm{D}: 110 \mathrm{~mm}, \mathrm{E}: 130 \mathrm{~mm}, \mathrm{~F}: 150 \mathrm{~mm}$. co: lignified cortical cell, en: endodermis, el: endodermis-like cells, lig: lignin accumulation. Scale $=25 \mu \mathrm{m}$. 


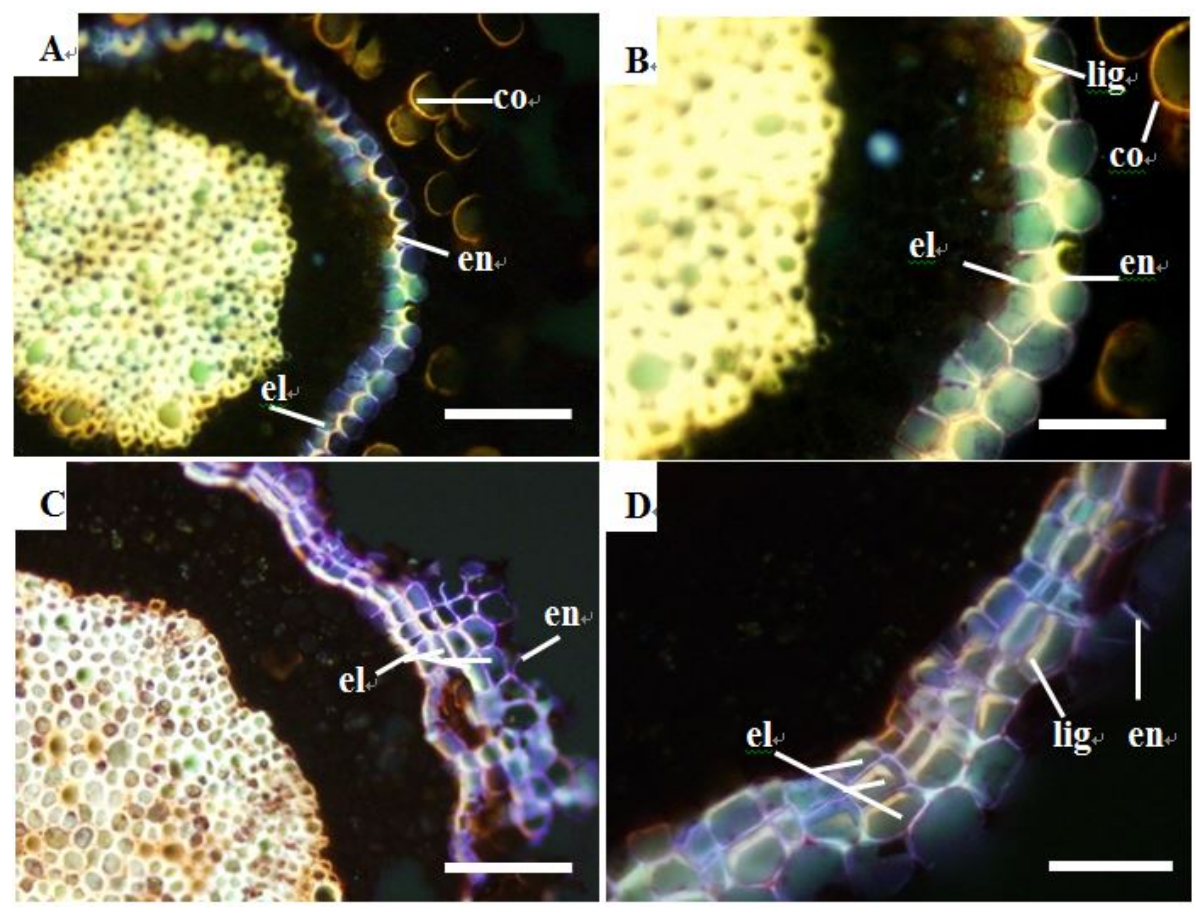

Fig. 4. Lignin-like accumulation at the endodermis and formation of new cell layers beyond the endodermis in pomegranate roots. Root samples were stained with berberine hemisulfate-aniline blue-safranin O. Lignified cell walls appear to be reddish orange and suberized layers appear to be milky white under the fluorescence microscopy. Distance from the root tip, panel A: $130 \mathrm{~mm}, \mathrm{C}: 150 \mathrm{~mm}$; B, D are enlargements of A, C, respectively. en: endodermis, el: endodermis-like cells, lig: lignin accumulation, co: lignified cortical cell. Scale $=50 \mu \mathrm{m}$ (Panels B, D); 100 $\mu$ m (Panels A, C).

Formation of lignified cell layers during secondary growth

The development of new cells with lignin accumulation is presented in Figs. 3D-3F and Fig. 4. When the surface color of roots changed from white to brown, periderm layers began to develop beyond the endodermis. At first, lignin-like deposit was observed in the endodermis cells with Casparian strip (Figs. 3D, 3E, 4A and 4B). This stage of endodermal development was termed as stage III because endodermal cell walls thickened with added layers of lignin. Then new cell layers formed due to cell division at the pericycle (Figs. 5A and 5B). Then as the central stele grew rapidly and xylem vessels increased, up to 3-4 new cell layers with lignin accumulation developed due to cell division at the phellogen (Figs. 4C, 4D, 5C and 5D) and all these new cell layers appeared milky white on the periphery and reddish orange on one side, "closed" centripetally. It implies that both biopolymers accumulated in the same cell layer. If tissues that stain reddish orange (mainly lignin) are scrutinized, difference in accumulation area was noticed. At the rhizodermis lignin-like accumulation appeared to be "open" centripetally resembling the letter "m" (Fig. 2) whereas it appeared to be "closed" centripetally resembling the letter " $w$ " at the cortical cells (Figs. 2F, 3F, 4A and 4B), the endodermis (Figs. 3E, 3F, 4A and $4 \mathrm{~B})$ and the new cells forming beyond the endodermis (Figs. 4C and 4D).

In Fig.6, developmental stages of these new cell layers occurring beyond the endodermis are presented. After the outermost tissues such as rhizodermis, exodermis, cortex, endodermis sloughed off due to the continuous enlargement of the central stele, new cell layers increased layer by layer to form up to 5-10 stratified layers (Figs. 6B and 6C). Each cell elongated tangentially and appeared to be rectangular or square-shaped (Figs. 6E and 6F). As roots matured, lignin-like deposit seen as vibrant reddish-orange auto fluorescence, became darker and broader in each cell (Fig. 6F). This kind of brick-like layout was quite unfamiliar to the traditional description of polyderm with alternating layers of suberized and non-suberized cell layers beyond the endodermis. In pomegranate roots, cell division at the phellogen was the cause of new cell layer formation in roots undergoing secondary growth (Figs. $5 \mathrm{C}$ and 5D) and accumulation of what seems to be mainly lignin and suberin occurred in the same cell layer. Therefore we concluded that it may be a unique type of periderm specific to Punicacea family. 


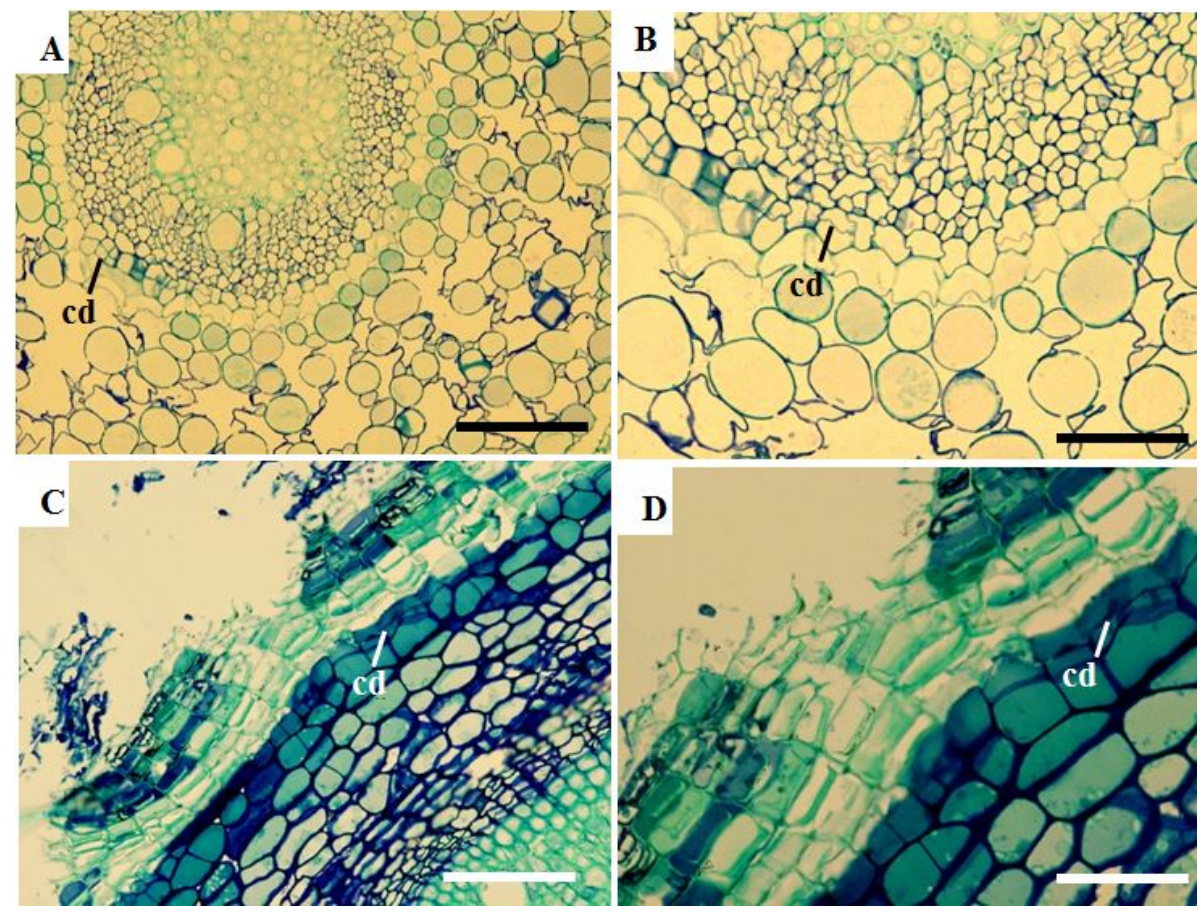

Fig. 5. Cell divisions occurring in pericycle and phellogen of pomegranate root. Older root samples different from Figs.2-4 were embedded in Technovit resin and stained with methylene blue. One or more tangential plates appeared in the cells at the pericycle and phellogen which caused cell division. Distance from the root tip, panel A: $80 \mathrm{~mm}$, C: 110 $\mathrm{mm}$; B, D are enlargements of A, C, respectively. cd: cell division. Scale $=50 \mu \mathrm{m}$ (Panels B, D); $100 \mu$ m (Panels A, C).

As the root aging progressed, the central stele continued to widen in diameter causing the outermost layers to shed off unevenly leaving triangular chunks of lignified tissues (Figs. 6A and 6C) at a number of places along the root circumference which were very similar to the formation of lenticels (Figs. 5C and 6D).

\section{Discussion}

In pomegranate roots, the Casparian strip formed at the exodermis earlier than the endodermis. It is a known that the endodermal Casparian strip blocks the free apoplastic passage of various ions, heavy metals and fluorescent dyes (Robards and Robb 1972, Nagahashi et al. 1974). It is possible that the Casparian strip at exodermis may be functioning similarly, as a filter or barrier to apoplastic movement like the endodermis in juvenile roots (Peterson et al. 1978, 1982; Peterson 1987, Lehmann et al. 2000). Details of exodermis permeability have been reviewed by Hose et al. (2001). We have observed similar anatomy previously in roots of grapevine (Song et al. 2011b, Tuladhar and Nii 2013), red bayberry (Song et al. 2011a) and feijoa (Nii et al. 2012) etc. It was concluded by Enstone and Peterson (1998) that endodermal Casparian strip was essential for root function whereas exodermal Casparian strips and suberin lamellae were only an adaptive feature.
Enstone et al. (2003) have used the term 'physiological sheath' for exodermis and endodermis that play an important role in root function.

The endodermis is the youngest and the innermost cortical layer (Lux and Luxova 2001). When endodermal maturity progressed up to stage III, endodermal cell walls thickened due to lignin accumulation. So far there have been reports that the Casparian strip forms due to suberin accumulation in the cell wall of endodermal cells (Peterson 1987, Peterson et al.1978, 1982) but Lux and Luxova (2001) have reported that the tertiary endodermis may become suberized or lignified. Lignin is a complex and highly variable biopolymer derived from the oxidative polymerization of cinnamyl alcohols bearing the three aromatic residues p-hydroxyphenyl, guaiacyl and syringyl (Freudenberg 1965, Whetten and Sederoff 1995). When a chemical analysis was conducted in maize (Zea mays L.) the lignin composition of Casparian strips (primary endodermal cell walls) showed high syringyl content and was similar to lignin in secondary cell walls of the tertiary endodermal cell walls whereas lignin in secondary cell walls contained higher amounts of p-hydroxyphenyl units (Zeier et al. 1999). In the present study, we observed suberin and lignin accumulation in endodermal cells (Figs. $3 \mathrm{D}-3 \mathrm{~F})$ and in every new cell layer that formed 

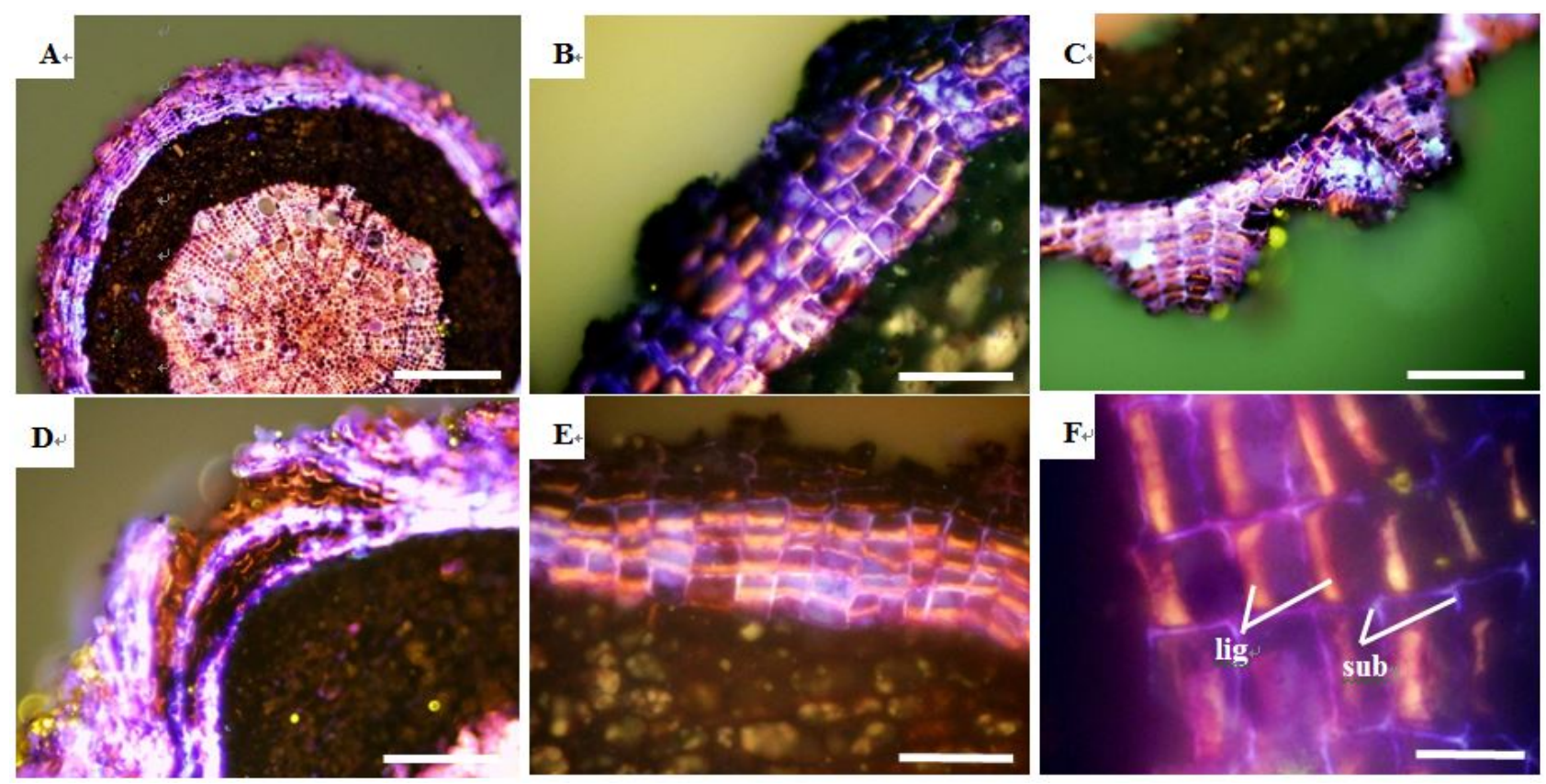

Fig. 6. Photomicrographs of cross-sections of pomegranate roots showing the formation of lignified cell layers at the periderm. Panel A shows multiple cell layers that are the outermost layers after endodermis, cortex, exodermis and rhizodermis shed off. Panel B is enlargement of panel A. Panel C shows triangular chunks of lignified and suberized periderm layers with openings in the middle. Panel D shows lenticel-like increase in thick-walled lignified cells at the root surface. Panel E shows lignin-like accumulation which is "closed" centripetally and suberin-like accumulation in the cell wall resembling a network. Panel F is enlargement of panel E. Distance from the root tip, panel A: $160 \mathrm{~mm}$, C: $150 \mathrm{~mm}, \mathrm{D}: 170 \mathrm{~mm}$, lig: lignin-like substances

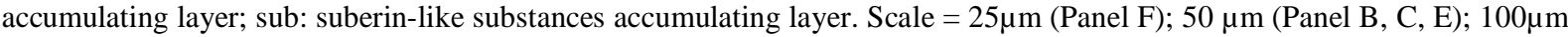
(Panel D); $500 \mu \mathrm{m}$ (Panel A).

beyond the endodermis (Fig. 4). Since the chemical analysis was not conducted in the present study, changes in lignin composition during the lignification process is unknown.

In our previous paper (Nii et al. 2012) we explained how polyderm layers form due to pericyclic cell division in feijoa (Myrtaceae) roots. Such regular accumulation of suberin and lignin was absent in pomegranate roots although it was clear that suberin accumulation preceded lignin accumulation at the endodermis (Figs. 3C and 3D). It is possible that lignin accumulation may be protecting the rapidly expanding endodermal walls from collapsing.

In the newly formed cells, though we could observe suberin accumulation, we can hardly conclude that they formed Casparian strips (Figs. 6E and 6F) since it was totally different from endodermis-like cells in feijoa polyderm. Referring to Mager (1932), Bond (1930) and Mylius (1913), Lux and Luxova (2001) have mentioned the endodermal Casparian network density formed by Casparian bands, which corresponds to each other in neighboring cells. In another report by Meyer and Peterson (2011) multiseriate Casparian bands existed in the periderm of Pelargonium hortorum roots. From our studies on root maturation in grapevines, we reported that suberin accumulated in the periderm cells formed by pericyclic cell division (Song et al. 2011b).

In the present study, the newly formed cell layers consisted lignin accumulation, in addition to suberization that distinguished it from periderm observed in grapevine roots. On the other hand, lignin and suberin did not accumulate in separate cell layers like the polyderm in fejoa roots. They accumulated in the same cell layer. Therefore it was difficult to conclude whether the observed tissue may be called polyderm. Existence of Casparian strip and suberin accumulation has been reported in periderm (Meyer and Peterson 2011, Tuladhar and Nii 2013), though lignin accumulation in periderm is uncommon. Alternative layers of lignin and suberin accumulating cell layers were reported in feijoa roots (Nii et al. 2012), however, in pomegranate roots even though lingo-suberic biopolymers could be detected, they did not exist in an alternating scheme.

In the present study, the width of the Casparian strip or suberin accumulating areas and lignified areas were not measured but the width of lignin in each cell was broader in mature roots. Suberin accumulation was visible in the cell wall of each cell that appeared to form a network. According to Lux and Luxova (2001), the role of the width of Casparian bands is related with the increased adherence of plasma membrane to the impregnated region of cell 
wall. Fahn (1964) has reported that the function of the network formed by Casparian bands as an apoplastic barrier was more effective when the protoplasts were attached to larger areas of the walls of the endodermal cells. Lignin deposit as phi-thickening was associated with mechanical support by Mackenzie (1979). Phi-thickening was non-existent in pomegranate roots but large amounts of lignin-like accumulation were seen in cell wall of every cell layer that formed due to cell division at phellogen. Important physiological properties of lignin include mechanical support, compressive strength, and plant defense based on its resistance to degradation (Campbell and Sederoff 1996). The fact that so much lignin accumulated in outermost tissues of pomegranate roots may be contributing to tolerate and adapt to various soil environments. The biochemical formation of lignin and the anatomical aspects of the lignification process like distribution of the lignin in the cell wall and its effect on cell wall properties have not been completely established (Kutscha and Grey 1970). Lignin research has gained steady momentum over the years and recently, an enzyme central to lignin biosynthetic pathway called caffeoyl shikimate esterase was described by Vanholme et al. (2013) that affects lignin deposit in Arabidopsis thaliana. Sachs et al. (1962) have reported that lignin inhibits biological attack of wood particularly by fungi and decreases wood's permeability to gases and liquids. Much needs to be uncovered about lignin accumulation in woody fruit tree roots.

The present study has been useful to uncover the prominent lignin accumulation in maturing pomegranate roots. However, further experiments are necessary to determine the effect of abiotic stress conditions like flooding or drought on the biopolymer accumulation in periderm layers and overall development of pomegranate root tissues. Root tissue density or tissue volume is a matter of prime interest anatomically and it is important when studying adaptive responses of plants to their environmental conditions. Since root cell wall is the first to be affected by any stress signal (Komatsu et al. 2010, Salvador et al. 2013), studies on cell wall modification and their function deserve more attention. In this study we uncovered a unique layout of lingo-suberic biopolymers in pomegranate roots from growth to maturity which may be a highly species specific matter.

\section{References}

Bond G 1930 The occurrence of cell division in the endodermis. Proc. Roy. Soc. Edinb. 50: 38-50.

Brundrett MC, Enstone DE, Peterson CA 1988 A berberine-aniline blue fluorescent staining procedure for suberin, lignin and callose in plant tissue. Protoplasma 146: 133-142.

Campbell MM, Sederoff RR 1996 Variations in lignin content and composition. Mechanisms of control and implications for the genetic improvement of plants. Plant Physiol. 110: 3-13.

Enstone DE, Peterson CA 1998 Effects of exposure to humid air on epidermal viability and suberin deposition in maize (Zea mays L.) roots. Plant Cell and Env.21: 837-844.

Enstone DE, Peterson CA, Ma F 2003 Root endodermis and exodermis: structure, function and responses to the environment. J. Plant Growth Regul. 21: 335-351.

Esau K 1970 Anatomy of Seed Plants. 2nd Edition. John Wiley and Sons, New York, p. 185.

Fahn A 1964 Some anatomical adaptations of desert plants. Phytomorph.14: 93-102.

Freudenberg K 1965 Lignin: its constitution and formation from $p$-hydroxycinnamyl alcohols. Science 148: 595-600.

von Guttenberg H 1968 Der primare Bau der Angiospermenwurzel. Handbuch der Pflanzenanatomie. Berlin/Stuggart: Gebruder Borntraegern 472.

Hiwale SS, More TA, Bagle BG 2011 Root distribution pattern in pomegranate 'Ganesh' (Punica granatum L.). Acta Hort. 890: 323-326.

Hose E, Clarkson DT, Steudle E, Schreiber L, Hartung W 2001 The exodermis a variable apoplastic barrier. J. Exp. Bot. 52: 2245-2264.

Komatsu S, Kobayashi Y, Nishizawa K, Nanjo Y, Furukawa, K 2010 Comparative proteomics analysis of differentially expressed proteins in soybean cell wall during flooding stress. Amino Acids 39: 1435-1449.

Kutscha NP, Grey JR 1970 The Potential of Lignin Research. Technical Bulletin 41. Maine Agricultural Experiment Station. University of Maine, Orono, Maine, pp. 1-20.

Lehmann H, Stelzer R, Holzamer S, Kunz U, Gierth M 2000 Analytical electron microscopical investigations on the apoplastic pathways of lanthanum transport in barley roots. Planta 211: 816-822.

Luhan M 1955 Das Abschlussgewebe der Wurzeln unserer Alpenpflanzen. Berichte der Deutschen Botanischen Gesellschaft 68: 87-92

Lux A, Luxova M 2001 Secondary dilation growth in the root endodermis. Recent Advances of Plant Root Structure and Function. Kluwer Academic Publishers, Netherlands, pp. 31-37.

Lux A, Morita S, Abe J, Ito K 2005 An improved method for clearing and staining free-hand sections and whole-mount samples. Ann. Bot. 96: 986-996.

Mackenzie KAD 1979 The development of the endodermis and phi layer of apple roots. Protoplasma 100: 21-23.

Mager M 1932 Beitrage zu kenntris de primaren wuzelrinde. Planta 16: 666-708.

Mann CET 1930 Studies in the root and shoot growth of strawberry. The origin, development and function of roots of the cultivated strawberry (Fragaria virginiana $\mathrm{x}$ chiloensis). Ann. Bot. 44: 56-84.

Meyer CJ, Peterson CA 2011 Casparian bands occur in the periderm of Pelargonium hortorum stem and root. Ann. Bot. 107: 591-598.

Moerschbacher BM, Noll U, Gorrichon L, Reisener HJ 1900 Specific inhibition of lignification breaks hypersensitive resistance of wheat to stem rust. Plant Physiol. 93: 465-470.

Mylius G 1913 Das Polyderm. Bib. Bot. 18: 1-119.

Nagahashi G, Thompson WW, Leonard RT 1974 The Casparian strip as a barrier to the movement of lanthanum 
in corn roots. Science 183: 670-671.

Nelson PE, Wilhelm S 1957 Some aspects of strawberry root. Hilgardia 26: 631-642.

Nii N, Ohtsuka S, Ye L, Song Y 2012 Formation of endodermis-like cells with Casparian strip and thick wall cells derived from pericycle in the roots of Feijoa sellowiana (Myrtaceae). J. Japan. Soc. Hort. Sci. 81: 314-319.

Nii N, Pan CX, Ogawa Y, Cui SM 2004 Anatomical features of the cell in-growth in the cortical cells outside the endodermis and the development of the Casparian strip in loquat trees. J. Japan. Soc. Hort. Sci. 73: 411-414.

Pan CX, Nakao Y, Nii N 2006 Anatomical development of phi thickening and the Casparian strip in loquat roots. J. Japan. Soc. Hort. Sci. 75: 445-449.

Peterson CA 1987 The exodermal Casparian band of onion blocks apoplastic movement of sulphate ions. J. Exp. Bot. 32: 2068-2081.

Peterson CA, Emanuel ME, Wilson C 1982 Identification of a Casparian band in the hypodermis of onion and corn roots. Can. J. Bot. 60: 1529-1535.

Peterson CA, Peterson RL, Robards AW 1978 A correlated histochemical and ultrastructural study of the epidermis and hypodermis of onion roots. Protoplasma 96: 1-21.

Robards AW, Robb ME 1972 The entry of ions and molecules into roots: an investigation using electron-opaque tracers. Planta 120: 1-12.

Sachs I, Clark I, Pew J 1962 Techniques to locate lignin in wood cells. Chem and Eng. News. 40: 41-42.

Salvador VH, Lima RB, Dos Santos WD, Soares AR, Bohm PAF, Marchiosi R, Ferrarese M, Ferrarese-Filho O 2013 Cinnamic acid increases lignin production and inhibits soybean root growth. PLoS ONE 8(7): e69105. doi:10.1371/journal.pone.0069105.

Song Y, Ye L, Nii, N 2011a Effects of soil water availability on development of suberin lamellae in the endodermis and exodermis and on cortical cell wall thickening in red bayberry (Myrica rubra Sieb. et Zucc.) tree roots. Sci. Hortic. 129: 554-560.

Song Y, Ye L, Tuladhar A, Nii N 2011b Anatomical development of cell structure including Casparian strip during root growth in grapevines. J. Japan. Soc. Hort. Sci. Sci. 80: 164-168.

Teixeira da Silva JA, Rana TS, Narzy D, Verma N, Meshram DT, Ranade SA 2013 Pomegranate biology and biotechnology: A review. Sci. Hortic. 160: 85-107.

Tripathi SM, Singh DK 2000 Molluscicidal activity of Punica granatum bark \& Canna indica root. Braz. J. Med. Biol. Res. 33: 1351-1355.

Tuladhar A, Nii N 2013 Anatomical changes of root thickening and shedding process of outer layers during secondary growth in grapevine roots. Sci. Rep. Fac. Agri. Meijo Univ. 49: 11-17. (in Japanese with English abstract).

Vanholme R, Cesarino I, Rataj K, Xiao Y, Sundin L, Goemine G, Kin H, Cross J, Morreel K, Araujo P, Welsh L, Haustraete J, McClellan C, Vanholme B, Ralph J, Simpson G, Halpin C, Boejan W 2013 Caeffeoyl Shikimate Esterase (CSE) is an enzyme in the lignin biosynthetic pathway in Arabidopsis. Science 341: 1103.

Whetten R, Sederoff L1995 Lignin biosynthesis. Plant Cell 7: 1001-1013.

Williamson B. 1984. Polyderm, a barrier to infection of red raspberry buds by Didymella applanata and Botrytis Cinerea. Ann. Bot. 53: 83-89.

Zeier J, Ruel K, Ryser U, Schreiber L 1999 Chemical analysis and immunolocalisation of lignin and suberin in endodermal and hypodermal/ rhizodermal cell walls of developing maize (Zea mays L.) primary roots. Planta 209: $1-12$.

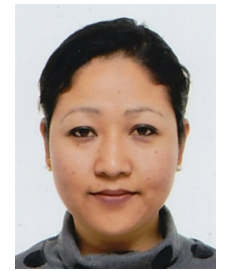

Ms. Astha Tuladhar's research interest is focused on anatomical studies of fruit tree roots under different abiotic stress conditions like drought and water-logging. 